\title{
Exome of Radiation-induced Rat Mammary Carcinoma Shows Copy-number Losses and Mutations in Human-relevant Cancer Genes
}

\author{
HITOMI MORIYAMA ${ }^{1,2,3}$, KAZUHIRO DAINO ${ }^{1}$, ATSUKO ISHIKAWA ${ }^{1}$, TATSUHIKO IMAOKA ${ }^{1,2}$, \\ MAYUMI NISHIMURA ${ }^{1}$, YUKIKO NISHIMURA ${ }^{1,4}$, MASARU TAKABATAKE ${ }^{1,2,5}$, TAKAMITSU MORIOKA ${ }^{1}$, \\ KAZUMASA INOUE ${ }^{2}$, MASAHIRO FUKUSHI ${ }^{2}$, YOSHIYA SHIMADA ${ }^{4,6}$ and SHIZUKO KAKINUMA ${ }^{1,2}$ \\ ${ }^{1}$ Department of Radiation Effects Research, National Institute of Radiological Sciences (NIRS), \\ National Institutes for Quantum and Radiological Science and Technology (QST), Chiba, Japan; \\ ${ }^{2}$ Department of Radiological Sciences, Graduate School of Human Health Sciences, \\ Tokyo Metropolitan University, Tokyo, Japan; \\ ${ }^{3}$ Present address: Konica Minolta, Inc., Tokyo, Japan; \\ ${ }^{4}$ Present address: Institute for Environmental Sciences, Aomori, Japan; \\ ${ }^{5}$ Present address: Georgetown University, Washington, DC, U.S.A.; \\ ${ }^{6}$ Executive Director, QST, Chiba, Japan
}

\begin{abstract}
Background/Aim: Our understanding of cancer risk from neutron exposure is limited. We aimed to reveal the characteristics of mammary carcinomas induced by neutrons. Materials and Methods: Mammary carcinomas obtained from female Sprague-Dawley rats irradiated at 7 weeks of age with 0.97 Gy neutrons or 4 Gy $\gamma$-rays and from non-irradiated rats were classified into luminal and non-luminal subtypes by immunohistochemistry. Their mutational landscapes were determined by whole-exome sequencing. Results: Neutrons significantly raised the incidence of luminal mammary carcinomas over the non-luminal subtype. Somatic mutations were identified in cancer genes involved in several signalling pathways, including Keap1/Nrf2, Pi3k/Akt and Wnt/3-catenin. Focal copy-number losses involving cancer genes were observed mainly in carcinomas from the irradiated rats. Conclusion: Neutrons increase the incidence of luminal mammary carcinomas, probably through gene mutations similar to those found in human breast cancers, and focal copy-number losses including cancer genes that are characteristics of radiation-induced mammary carcinomas.
\end{abstract}

This article is freely accessible online.

Correspondence to: Kazuhiro Daino and Shizuko Kakinuma, Department of Radiation Effects Research, National Institute of Radiological Sciences, National Institutes for Quantum and Radiological Science and Technology, 4-9-1 Anagawa, Inage-ku, Chiba 263-8555, Japan. Tel: +81 432064053, Fax: +81 432064138, e-mail: daino.kazuhiro@qst.go.jp (KD), kakinuma.shizuko@qst.go.jp (SK)

Key Words: Neutron, breast cancer, genomic aberrations.
Epidemiological studies on atomic bomb survivors and patients who have undergone radiotherapy have established that ionizing radiation is a risk factor for breast cancer (1). Neutrons are high linear energy transfer (LET) radiation and produce more complex DNA damage, with stronger carcinogenetic effects as compared with low LET radiation, such as $\gamma$-rays (2). Thus, there is concern about the breast cancer risk from neutron exposure caused by nuclear accidents and as a secondary radiation during proton therapy, which is increasingly used in the clinical setting (3-5).

Animal models of carcinogenesis have provided crucial information for estimating the radiation-induced cancer risk in humans when data from human populations are lacking or limited (6). In contrast, comparisons between rodent and human data with respect to spontaneous and chemically induced tumours have shown that particular gene alterations involved in specific tumour types tend to differ across species (6). Therefore, additional data on the carcinogenic mechanisms of radiation exposure are needed to increase the reliability of extrapolation from rodent data the risk in human populations.

The rat is a widely used model to study the risks and mechanisms of breast carcinogenesis because rat mammary carcinomas are similar to human breast cancer with regard to their hormone dependence and pathology $(7,8)$. We have previously conducted a series of experiments to quantify the incidence of neutron-induced mammary carcinomas in rats $(9,10)$. Our most recent study revealed that neutrons and $\gamma$ rays (at a dose of $0.5 \mathrm{~Gy}$ ) increase mainly the incidence of luminal mammary carcinoma in rats, probably via genetic aberrations associated with human breast cancer (11). In this 
previous report, we used array-based comparative genomic hybridization (array-CGH) to identify multiple DNA copynumber aberrations that affect genes for which mutations had been previously reported in human breast cancer. However, none of these aberrations displayed any significant differences among the carcinomas in non-irradiated, neutronirradiated and $\gamma$-ray-irradiated groups. In addition, an important limitation of the array-CGH is the inability to detect gene mutations, and thus further study was warranted using more comprehensive techniques, such as nextgeneration sequencing.

Breast cancer is a molecularly heterogeneous disease and is classified into several subtypes such as luminal, triple-negative and human epidermal growth factor receptor 2 (HER2)enriched (12). The subtypes of breast cancer that occur in humans after X-ray exposure have been previously investigated (13-15). However, there has been no consistent evidence that radiation preferentially induces specific subtypes. We thus performed immunohistochemistry and whole-exome sequencing to investigate the subtype(s) and mutational landscape of neutron-induced mammary carcinomas. In this study, to clarify the features of mammary carcinomas induced by neutrons, we further analysed archival mammary carcinomas (16) of rats irradiated with neutrons or $\gamma$-rays at the highest doses ( $0.97 \mathrm{~Gy}$ neutron beams or $4 \mathrm{~Gy}$ $\gamma$-rays) in our previous animal experiments (9).

\section{Materials and Methods}

Tumour samples. Mammary carcinoma samples were obtained from our previous animal experiments $(9,17)$, which were approved by the Institutional Animal Care and Use Committee of the National Institutes for Quantum and Radiological Science and Technology (approval No. 07-1016), and were performed in accordance with the Fundamental Guidelines for Proper Conduct of Animal Experiment and Related Activities in Academic Research Institutions under the jurisdiction of the Ministry of Education, Culture, Sports, Science and Technology of Japan. Detailed procedures for the animal experiments have been described $(9,17)$. Briefly, female SpragueDawley (Jcl:SD) rats (CLEA Japan Inc., Tokyo, Japan) were wholebody irradiated with ${ }^{9} \mathrm{Be}(\mathrm{d}, \mathrm{n} \gamma){ }^{10} \mathrm{~B}$ fast neutrons $(0.97 \mathrm{~Gy}$; mean energy, $2 \mathrm{MeV}$ ) or ${ }^{137} \mathrm{Cs} \gamma$-rays (4 Gy) at 7 weeks of age or were left unirradiated. The biological effects of fast neutrons are known to be high at several $\mathrm{MeV}$ (18) and the neutron energy was relevant to that of fission neutrons. Mammary carcinomas were identified by weekly palpation until the age of 90 weeks. All rats were fed a CE2 diet (CLEA Japan) and were provided sterile water ad libitum. They were maintained under specific pathogen-free conditions in autoclaved cages maintained on a 12-h light/12-h dark cycle. We sacrificed rats and collected their tissues if they showed any signs of deterioration such as rapid body mass loss, severe anaemia or excessive tumour burden. Mammary carcinomas and normal mammary glands from the same animal were stored at $-80^{\circ} \mathrm{C}$ for molecular analysis and as formalin (10\%)-fixed samples for pathological analysis. The characteristics of carcinomas analysed in this study are shown in Table I.
Tumour subtyping. Subtyping of mammary carcinomas was performed as described (11). Briefly, formalin-fixed paraffinembedded tissues were sectioned ( $\sim 3 \mu \mathrm{m}$ thick). The sections, which were placed on silane-coated slides were deparaffinized with xylene, rehydrated through a graded ethanol series and immunostained with antibodies against oestrogen receptor $\alpha(\mathrm{ER} \alpha)$ (NCL-L-ER-6F11, clone 6F11; Leica Biosystems, Nussloch, Germany; 1:400), progesterone receptor (PgR) (AM1118PU-S, clone SP42; Acris Antibodies, Herford, Germany; 1:400), HER2 (MS-730-P0, clones e2-4001+3B5; Thermo Fisher Scientific, MA, USA; 1:100) and the proliferation marker Ki-67 (M3064, clone SP6; Spring Bioscience, Pleasanton, CA, USA; 1:200). Methods of immunohistostaining, scanning and evaluation have been described (11). Threshold for positivity of a carcinoma was set at $1 \%$ for $\mathrm{ER} \alpha$ and $\mathrm{PgR}$; the threshold of Ki-67 positivity was set at the median percentage (15.9\%); for HER2, carcinomas were classified as reported (12). The luminal subtype was defined as HER2 ${ }^{-}$and $E R \alpha^{+}$and/or $\mathrm{PgR}^{+}$, and the non-luminal subtype was any other combination of markers according to the standard classification of human breast cancers (12).

DNA sample preparation. Genomic DNA was extracted from frozen mammary carcinoma or normal mammary gland tissue samples as described (11). Briefly, we prepared 20 - $\mu$ m-thick sections from optimal cutting temperature compound-embedded frozen tissue on a membrane slide (MMI Membrane Slides RNA free, Molecular Machines \& Industries, Glattbrugg, Switzerland). These sections were briefly fixed in 2-propanol and stained with hematoxylin and eosin. Cancerous epithelial cells were captured using a microdissection system under the supervision of a pathologist (T.M.), and genomic DNA was isolated from these cells using a QIAmp DNA Micro Kit (Qiagen, Hilden, Germany).

Whole-exome sequencing and data analysis. Whole-exome sequencing was performed on rat mammary carcinoma and matched normal mammary gland tissue samples with sufficient quantity and quality of genomic DNA as described (19). In brief, genomic DNA was fragmented by sonication (Covaris, M\&S Instruments Inc., Tokyo, Japan) to $150 \mathrm{bp}$ and was further purified using Agencourt AMPure XP beads. Then, 100 ng of DNA was ligated to specific adapters during library preparation (KAPA Library Preparation Kit, Kapa Biosystems, Woburn, MA, USA). Exon capture probes were designed for targeting available rat genes from the rat reference genome (rn5) RefSeq transcripts, including a total of 15,854 genes, and unannotated transcripts, including 24 known driver genes (i.e. Pik3ca, Kmt2c, Arid1b, Afdn, Fbxw7, Ncor1, Spen, Med23, Kdm6a, Kmt2d, Atr, Smad4, Atrx, Cux1, Gnas, Phf6, Ect2l, Pbrm1, Tet2, Asxl1, Braf, Bub1b, Ercc5 and Zfp36l1) in human breast cancers (20). Each library was prepared with sample-specific barcodes and underwent exome enrichment (SeqCap EZ Developer Library, Roche, Tokyo, Japan). Several libraries were pooled and sequenced on NextSeq 500 system (Illumina Inc., Tokyo, Japan).

Data were processed using the pipeline prepared by Amelieff Co. Ltd (Tokyo, Japan) as described previously (19). Briefly, the reads were trimmed by removing low-quality bases and removed if they were shorter than 32 bases or if $>80 \%$ of any individual read had a quality rating of $<20$ using the QCleaner tool (ver. 4.1) developed by Amelieff Co. Ltd. The resulting reads were aligned to the rat reference genome (rn6) by the use of the Burrows-Wheeler Alignment tool (ver. 0.7.12). Duplicate reads were removed with SAMtools (ver. 1.2), and base quality recalibration and realignment around insertions/deletions 
Table I. Characteristics of rat mammary carcinomas analysed in this study.

\begin{tabular}{|c|c|c|c|c|}
\hline Sample ID & Group & Subtype & Age at detection (weeks) & Age at autopsy (weeks) \\
\hline К0679MT2 & No irradiation & Luminal & 78 & 93 \\
\hline K0813MT4 & No irradiation & Luminal & Discovered at autopsy & 90 \\
\hline K1404MT1 & No irradiation & Non-luminal & 83 & 92 \\
\hline K1465MT1 & No irradiation & Luminal & 51 & 81 \\
\hline K2364MT1 & No irradiation & Luminal & 74 & 91 \\
\hline K2403MT1 & No irradiation & Luminal & 57 & 92 \\
\hline K2455MT1 & No irradiation & Luminal & 54 & 66 \\
\hline K2476MT3 & No irradiation & Non-luminal & 50 & 90 \\
\hline K2608MT1 & No irradiation & Luminal & 64 & 92 \\
\hline K2861MT1 & No irradiation & Luminal & 81 & 90 \\
\hline K2264MT1 & Neutrons & Luminal & 38 & 68 \\
\hline K2288MT1 & Neutrons & Luminal & 30 & 59 \\
\hline K2315MT1 & Neutrons & Luminal & 31 & 61 \\
\hline K2462MT1 & Neutrons & Luminal & 39 & 71 \\
\hline K2528MT1 & Neutrons & Luminal & 16 & 34 \\
\hline K2578MT1 & Neutrons & Luminal & 23 & 37 \\
\hline K2686MT2 & Neutrons & Luminal & 33 & 48 \\
\hline K2975MT1 & Neutrons & Luminal & 52 & 71 \\
\hline К0886MT2 & $\gamma$-rays & Luminal & 17 & 24 \\
\hline K0898MT1 & $\gamma$-rays & Luminal & 23 & 38 \\
\hline К0952MT1 & $\gamma$-rays & Luminal & 24 & 44 \\
\hline K1009MT2 & $\gamma$-rays & Luminal & 41 & 52 \\
\hline K1069MT2 & $\gamma$-rays & Luminal & 44 & 60 \\
\hline K1157MT2 & $\gamma$-rays & Luminal & 52 & 71 \\
\hline K1163MT3a & $\gamma$-rays & Undetermined & 76 & 86 \\
\hline K1180MT1 & $\gamma$-rays & Luminal & 35 & 74 \\
\hline K1254MT8 & $\gamma$-rays & Non-luminal & 43 & 82 \\
\hline K1328MT4 & $\gamma$-rays & Luminal & 91 & 98 \\
\hline
\end{tabular}

aThis sample was obtained from an animal that was found dead and was not subjected to immunohistochemistry.

(InDels) were performed using the Genome Analysis Tool kit (ver. 1.613). Somatic single-nucleotide variants (SNVs) or InDels in tumours were called with the VarScan 2 software (ver. 2.4.3). A false-positive filter was then applied to remove sequencing- or alignment-related artifacts. Variants were annotated and the effect on coding sequences predicted using SnpEff software (ver. 4.3). We also required that the variant allele be present in $\geq 10 \%$ of tumour reads and that there were no representations of normal tissue reads. Control-FREEC software (ver. 10.8) was used to identify copy-number changes in tumours as compared with normal tissue from the same animal. Segments that exhibited a copy-number change that was statistically significant relative to normal ploidy were extracted $(p<0.05$, Wilcoxon and Kolmogorov-Smirnov tests). We used the $\mathrm{R}$ package Mutational Patterns (ver. 1.4.2) (https://www.bioconductor.org/packages/release/ bioc/html/MutationalPatterns.html) to extract and analyse the mutational spectrum of tumours.

Statistical analysis. Statistical analysis was performed using the statistical software $\mathrm{R}$ with the aid of the graphical user interface EZR (Jichi Medical University, Saitama, Japan) (21). Comparisons among three groups were performed with the Kruskal-Wallis test. Comparisons between two groups were performed with the MannWhitney $U$-test. The correlation coefficient was calculated using Spearman's rank correlation coefficient. Fisher's exact test was used to test the significance of differences in the number of palpable carcinomas or the subtypes of carcinomas. The significance of difference between the means was analysed by F-test. A $p<0.05$ was considered statistically significant.

\section{Results}

Neutron exposure increases the risks of luminal and nonluminal rat mammary carcinomas. Here, we investigated mammary carcinomas that developed in two groups of female rats from our previous studies $(9,17)$, which were irradiated i) with neutrons ( $0.97 \mathrm{~Gy}, n=24)$ or ii) with $\gamma$-rays (4 Gy, $n=20$ ), as well as a group of matched non-irradiated rats $(n=285)$. The incidence, tumour number, hazard ratio (i.e. ratio of the probability of having a new carcinoma per unit time) and the age at which mammary carcinomas were first detected in these groups are summarized in Table II. Neutron or $\gamma$-ray exposure significantly increased the incidence and hazard ratio of mammary carcinomas with a significant reduction in the age at which the carcinomas were first detected, as compared with the non-irradiated controls.

To examine the subtype(s) of mammary carcinomas in the non-irradiated and neutron- and $\gamma$-ray-irradiated groups, we 
Table II. Characteristics of the cohort of rats included in this study ${ }^{a}$.

\begin{tabular}{lccc}
\hline Feature & No irradiation & Neutrons & $\gamma$-rays \\
\hline Rats with carcinoma $^{\mathrm{b}}$ & $57 / 285(20 \%)$ & $18 / 24(75 \%)^{* * *}$ & $13 / 20(65 \%) * * *$ \\
Carcinomas available $^{\mathrm{c}}$ & 45 & 24 & 9 \\
Hazard ratio [95\%CI] $^{\text {Weeks of age at detection }}{ }^{\mathrm{d}}$ & 1.0 & $26.9[13.9-52.1]^{* * *}$ & $10.6[5.6-20.3]^{* * *}$ \\
& $66.3 \pm 18.0(43)$ & $34.0 \pm 14.8 * * *(17)$ & $47.2 \pm 22.5 * *(13)$ \\
\hline
\end{tabular}

aData from a previous experiment $(9,17)$ were used for this analysis. bRats with carcinoma/total number of rats in each group (percentage of rats with carcinoma). ${ }^{c}$ Some rats had multiple mammary carcinomas. ${ }^{\mathrm{d}}$ Mean $\pm \mathrm{SD}$ (number of palpable carcinomas). $* * p<0.01 ; * * * p<0.001 v s$. no irradiation. 95\% CI: 95\% confidence interval.

then performed immunohistochemical staining for $\mathrm{ER} \alpha, \mathrm{PgR}$, HER2 and Ki-67 in all available tumours (Table II). The percentage of positive cells for each antigen did not differ significantly between the groups (Table III). Based on the immunohistochemistry results, we classified the mammary carcinomas as the luminal or non-luminal subtype. The hazard ratio for palpable luminal mammary carcinomas was significantly higher in the neutron- and $\gamma$-ray-irradiated groups as compared with the non-irradiated groups (Table IV and Figure 1a). Neutron exposure also increased the hazard ratio of palpable non-luminal carcinomas (Table IV and Figure 1b), although the number of non-luminal carcinomas was relatively small in the neutron-irradiated group. Taken together, these results indicate that neutron exposure increases the risk of luminal and non-luminal mammary carcinomas and that the luminal subtype was mostly involved in the increased incidence of mammary carcinomas in neutron-irradiated rats.

Mutational landscape of spontaneous and neutron- and $\gamma$ ray-induced rat mammary carcinomas. To profile the somatic mutation spectrum of spontaneous and neutron- or $\gamma$-ray-induced mammary carcinomas, whole-exome sequencing was carried out on rat mammary carcinomas from the three groups (non-irradiated, $n=10$; neutronirradiated, $n=8 ; \gamma$-ray-irradiated, $n=10)$. As shown in Figure $2 \mathrm{a}$, no significant differences in the number of SNVs) or InDels were observed among the carcinomas from the three groups, i.e. non-irradiated (mean $=84.7$; range $=70-96$ ), neutron-irradiated (mean=83.4; range $=61-109)$ and $\gamma$-rayirradiated $($ mean $=85.3$; range $=54-117)$. However, mammary carcinomas from the neutron- and $\gamma$-ray-irradiated groups showed a large variation in the number of SNVs and InDels among individual cases as compared with spontaneously developed carcinomas. This was statistically significant for the $\gamma$-ray-irradiated group and when the neutron- and $\gamma$-rayirradiated groups were combined ( $p<0.05$, F-test). The size of insertions and deletions detected in the carcinomas was also similar among the groups (Figure $2 b$ ). In contrast, the number of single-nucleotide insertions was significantly lower in the carcinomas from the $\gamma$-irradiated group as
Table III. Immunohistochemical staining for ER $\alpha, P g R$ and HER2 in rat mammary carcinomas.

\begin{tabular}{lccc}
\hline Marker & \multicolumn{3}{c}{ Positive cells $(\%)$} \\
\cline { 2 - 4 } & No irradiation & Neutrons & $\gamma$-rays \\
\hline ER $\alpha$ & $21.5 \pm 15.8^{\mathrm{a}}$ & $20.7 \pm 12.2$ & $9.2 \pm 7.2$ \\
PgR & $14.0 \pm 15.8$ & $9.9 \pm 11.4$ & $8.1 \pm 7.8$ \\
HER2 & $5.7 \pm 8.3$ & $2.3 \pm 5.4$ & $0.9 \pm 2.6$ \\
Ki-67 & $19.2 \pm 13.2$ & $20.0 \pm 3.8$ & $11.8 \pm 10.2$ \\
\hline
\end{tabular}

aPercentage of positive cells (mean $\pm \mathrm{SD})$.

compared with the other two groups, although the underlying mechanisms for this difference are unknown (Table V). We did not find any other significant differences among the carcinomas in the three groups with regard to the number or spectrum of mutations, the subtype or the age at detection.

In many cancers, the number of somatic mutations increases with age $(22,23)$. However, no correlation was observed between the number of SNVs in the carcinomas and the age at tumour detection by palpation (data not shown). Cancers do harbour a variable number of somatic mutations that accumulate during their growth as a consequence of diverse cellular process, including the impairment of DNA repair and exposure to endogenous or exogenous DNAdamaging agents $(22,24)$. To compare the number of somatic mutations per growth period of mammary carcinomas from non-irradiated and neutron- and $\gamma$-ray-irradiated groups, we examined the relationship between the numbers of SNVs in the carcinomas and the periods from first palpation of the carcinomas to autopsy. As shown in Figure 3, whereas a significant positive correlation was observed between the total number of somatic mutations (SNVs and InDels) and the growth period of mammary carcinomas in the non-irradiated and neutron-irradiated groups, no correlation was observed in the $\gamma$-ray-irradiated group. This result suggests the involvement of some variable factors in the initiation or promotion of breast carcinogenesis induced by $\gamma$-ray- 
Table IV. Characteristics of rat mammary carcinoma development by subtype.

\begin{tabular}{|c|c|c|c|c|}
\hline \multirow[t]{2}{*}{ Feature } & \multirow[t]{2}{*}{ Subtype } & \multicolumn{3}{|c|}{ Treatment group } \\
\hline & & No irradiation & Neutrons & $\gamma$-rays \\
\hline \multirow[t]{2}{*}{ Number of palpable carcinomas ${ }^{b}$} & $\mathrm{~L}$ & $22(67 \%)$ & $21(91 \%)^{\dagger}$ & $8(89 \%)$ \\
\hline & NL & $11(33 \%)$ & $2(9 \%)$ & $1(11 \%)$ \\
\hline \multirow[t]{2}{*}{ Hazard ratio $[95 \% \mathrm{CI}]$} & $\mathrm{L}$ & 1.0 & $36.9[15.6-87.3]^{* * *}$ & $14.0[5.8-33.6]^{* * *}$ \\
\hline & NL & 1.0 & $7.8[1.6-38.3]^{*}$ & $3.4[0.4-27.1]$ \\
\hline \multirow[t]{2}{*}{ Weeks of age at detection ${ }^{c}$} & $\mathrm{~L}$ & $66.8 \pm 17.6$ & $41.6 \pm 12.6^{* * *}$ & $40.9 \pm 23.5 * *$ \\
\hline & NL & $74.3 \pm 18.9$ & $48.7 \pm 18.0$ & 43.0 \\
\hline
\end{tabular}

aL: Luminal; NL: non-luminal. bSome samples were obtained from an animal that was found dead and were not subjected to immunohistochemistry. ${ }^{\mathrm{c}}$ Mean \pm SD. ${ }^{\dagger} p=0.05,{ }^{*} p<0.05,{ }^{* *} p<0.01,{ }^{* * *} p<0.001 v s$. no irradiation. 95\%CI: $95 \%$ confidence interval.

exposure. In contrast, when the carcinomas of all groups were collectively analysed, a significant positive correlation was observed between the total number of somatic mutations (SNVs and InDels) and the duration of tumour growth (Figure 4a). In addition, a significant positive correlation was observed between the number of $\mathrm{C}: \mathrm{G}>\mathrm{T}: \mathrm{A}$ transitions at $\mathrm{CpG}$ sites, which is known as an age-associated mutation (22), and the duration of tumour growth (Figure 4b). Although the underlying mechanisms are unknown, we also observed a significant positive correlation between the number of $\mathrm{T}: \mathrm{A}>\mathrm{C}: \mathrm{G}$ transitions and the duration of tumour growth (Figure 4c).

To compare the mutational spectrum of mammary carcinomas from non-irradiated and neutron- and $\gamma$-rayirradiated groups, we then analysed the frequency of seven single base-pair substitutions in the carcinomas based on the observation of a comparable number of SNVs between the carcinomas from three groups. As shown in Figures 5a and 6 and Table $\mathrm{V}$, the mutation spectrum of single base-pair substitutions was dominated by $\mathrm{C}: \mathrm{G}>\mathrm{T}: \mathrm{A}$ transitions, and this was common among spontaneous and neutron- and $\gamma$-rayinduced carcinomas. In contrast, although no statistically significant difference was found, an increase in C:G>A:T transversions, which are induced by reactive oxygen species (ROS) (25), was observed in some mammary carcinomas in the irradiated groups (sample IDs K2264MT1, K2462MT1, K2578MT1 and K0886MT2) as compared with those in the non-irradiated group. To further characterize the mutational spectrum of spontaneous and neutron- and $\gamma$-ray-induced rat mammary carcinomas, we then performed a mutational signature analysis (22). As shown in Figure 5b, the mutational patterns of the carcinomas showed similarities to the mutational signatures observed in human breast cancers (namely signatures 1,5 and 30) as listed in the Catalogue of Somatic Mutations in Cancer (COSMIC) database (26). This analysis further revealed that the mutational patterns in a subset of the carcinomas (grouped into cluster A) were similar to the signatures
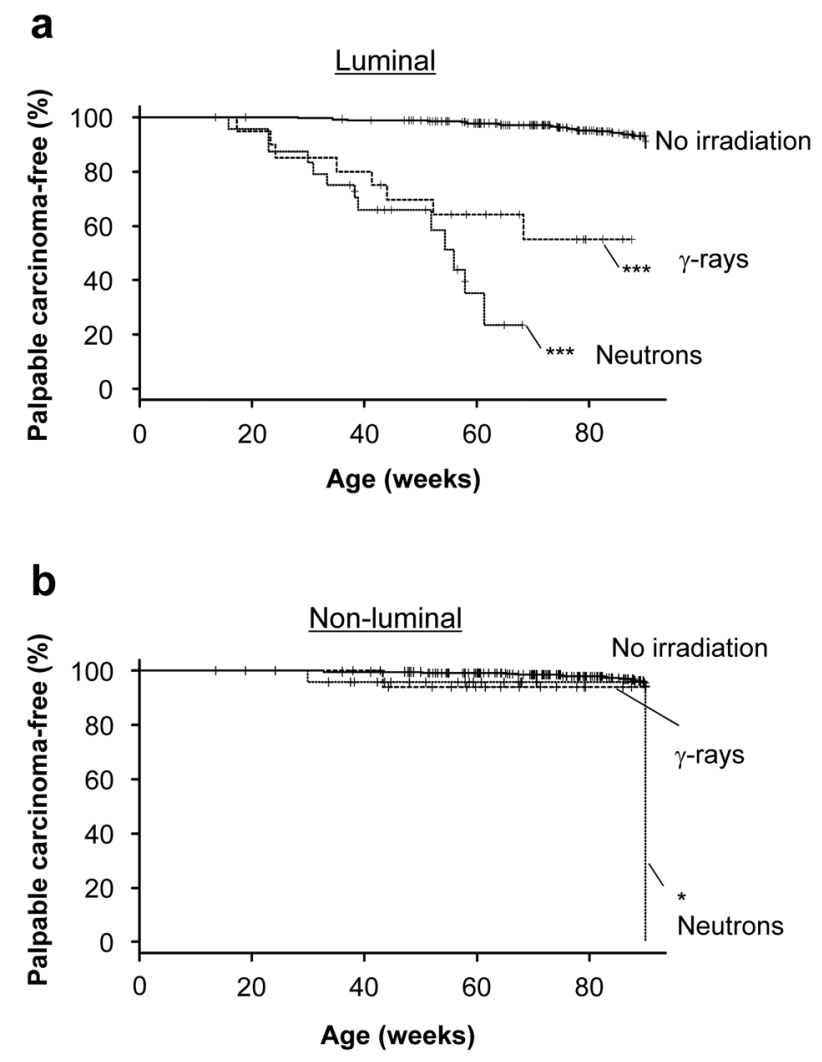

Figure 1. Incidence of mammary carcinoma among the three treatment groups of rats. $(a, b)$ Kaplan-Meier plots showing the onset of luminal (a) and non-luminal (b) palpable mammary carcinomas following irradiation with neutrons or $\gamma$-rays and the spontaneous development of carcinomas in the non-irradiated control. $* p<0.05$, ***p $<0.001 \mathrm{vs}$. no irradiation.

associated with mismatch repair deficiency (signatures 6,15 and 20). The remaining carcinomas were then grouped into two clusters: i) cluster B, which showed a similarity to the signatures for tobacco exposure (signatures 4 and 29) and BRCA 
a

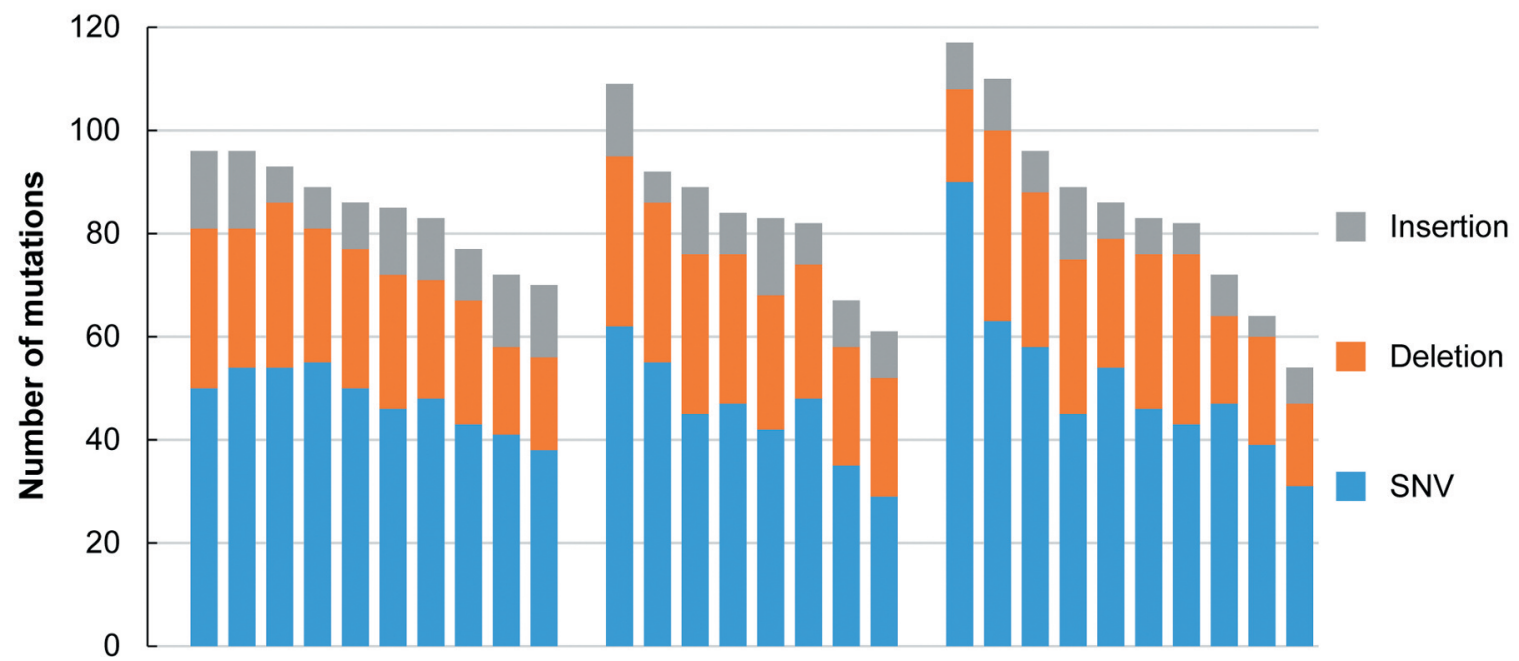

Subtype $\square \square \square \square \square \square \square \square \square \square$ Age at detection $\square$

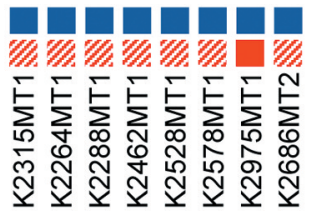

Neutrons

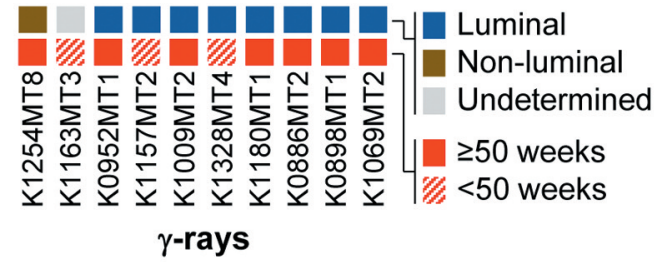

b

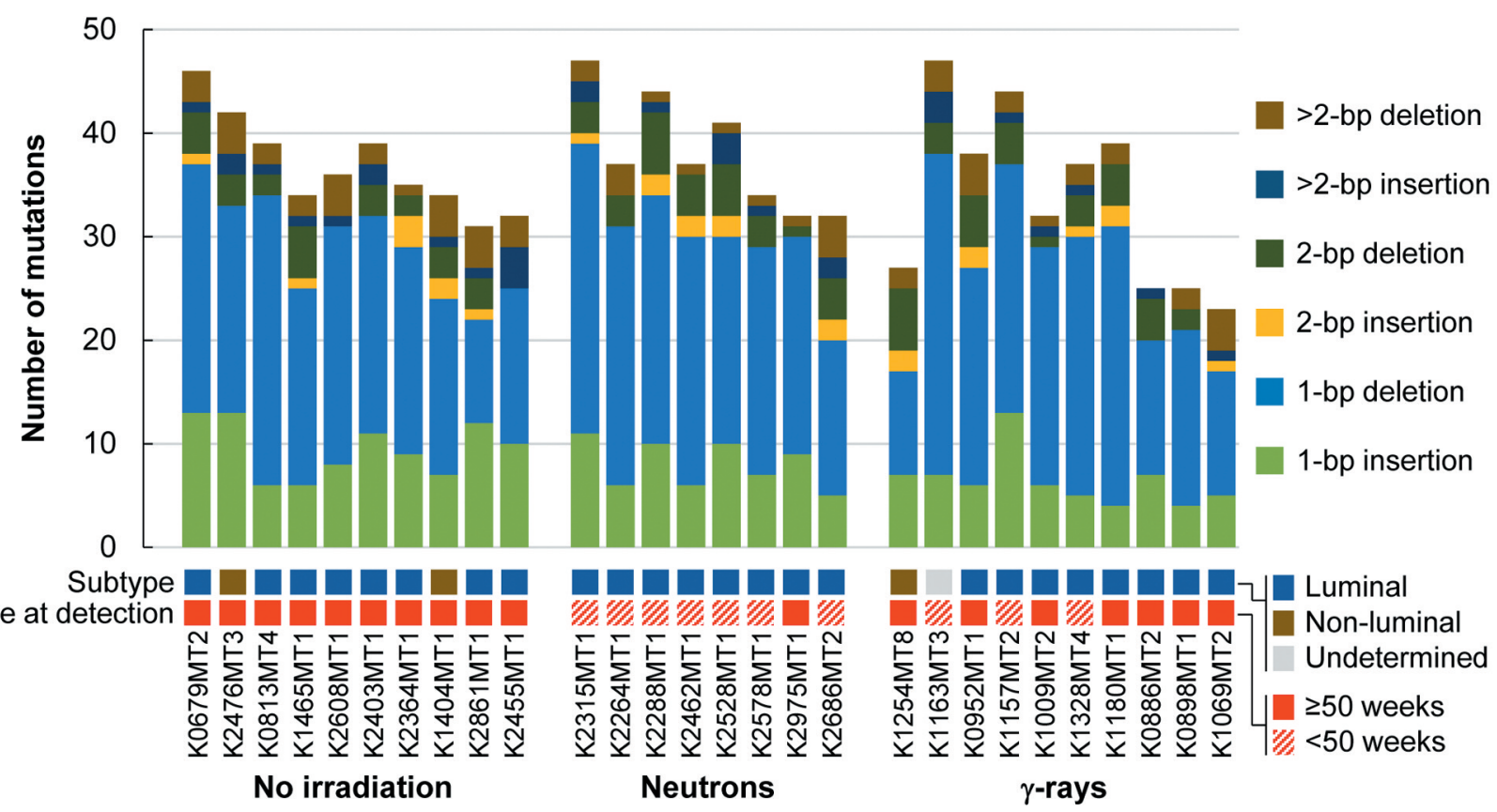

Figure 2. The number of somatic mutations identified in rat mammary carcinomas. (a) Mutations are separated into single nucleotide variants (SNVs), insertions and deletions. (b) The number of insertions and deletions (InDels) classified by their length. 
Morimyama et al: Mutational Landscape of Neutron-induced Mammary Carcinoma

Table V. The pattern and number of somatic mutations detected in rat mammary carcinomas.

\begin{tabular}{|c|c|c|c|c|c|}
\hline Mutation pattern & No irradiation & Neutrons & $\gamma$-rays & $p$-Value & Adjusted $p$-value \\
\hline \multicolumn{6}{|l|}{ SNVs } \\
\hline Total number of SNVs & $47.9 \pm .5^{\mathrm{a}}$ & $45.4 \pm 9.8$ & $51.6 \pm 15.5$ & 0.77 & NA \\
\hline $\mathrm{C}: \mathrm{G}>\mathrm{T}: \mathrm{A}$ (at non-CpG sites) & $11.2 \pm 3.0$ & $9.8 \pm 4.1$ & $12.0 \pm 5.9$ & 0.50 & NA \\
\hline $\mathrm{C}: \mathrm{G}>\mathrm{T}: \mathrm{A}$ (at $\mathrm{CpG}$ sites) & $6.2 \pm 2.3$ & $7.1 \pm 2.0$ & $5.6 \pm 3.3$ & 0.36 & NA \\
\hline $\mathrm{C}: \mathrm{G}>\mathrm{A}: \mathrm{T}$ & $7.9 \pm 3.4$ & $10.1 \pm 5.1$ & $10.5 \pm 4.6$ & 0.45 & NA \\
\hline $\mathrm{C}: \mathrm{G}>\mathrm{G}: \mathrm{C}$ & $4.2 \pm 2.1$ & $2.4 \pm 1.4$ & $4.8 \pm 2.7$ & 0.10 & NA \\
\hline $\mathrm{T}: \mathrm{A}>\mathrm{C}: \mathrm{G}$ & $8.5 \pm 1.5$ & $6.3 \pm 1.9$ & $8.2 \pm 2.7$ & 0.06 & NA \\
\hline $\mathrm{T}: \mathrm{A}>\mathrm{A}: \mathrm{T}$ & $5.9 \pm 2.3$ & $5.3 \pm 1.3$ & $6.5 \pm 2.6$ & 0.41 & NA \\
\hline $\mathrm{T}: \mathrm{A}>\mathrm{G}: \mathrm{C}$ & $4.0 \pm 1.6$ & $4.5 \pm 2.3$ & $4.0 \pm 1.7$ & 0.60 & NA \\
\hline \multicolumn{6}{|l|}{ InDels } \\
\hline Total number of insertions & $11.7 \pm 2.8$ & $10.3 \pm 3.1$ & $8.0 \pm 2.5^{\dagger}$ & 0.04 & 0.03 \\
\hline Total number of deletions & $25.1 \pm 4.6$ & $27.8 \pm 3.6$ & $25.7 \pm 7.0$ & 0.66 & NA \\
\hline 1-bp insertions & $9.5 \pm 2.6$ & $8.0 \pm 2.1$ & $6.4 \pm 2.5^{\dagger}$ & 0.04 & 0.03 \\
\hline 1-bp deletions & $19.7 \pm 4.7$ & $22.4 \pm 3.6$ & $20.3 \pm 6.6$ & 0.47 & NA \\
\hline 2-bp insertions & $0.8 \pm 1.0$ & $1.1 \pm 0.9$ & $0.8 \pm 0.9$ & 0.70 & NA \\
\hline 2-bp deletions & $2.5 \pm 1.5$ & $3.6 \pm 1.4$ & $3.2 \pm 1.7$ & 0.31 & NA \\
\hline$>2$-bp insertions & $1.4 \pm 1.0$ & $1.1 \pm 1.1$ & $0.8 \pm 0.9$ & 0.35 & NA \\
\hline$>2$-bp deletions & $2.9 \pm 1.0$ & $1.8 \pm 1.1$ & $2.2 \pm 1.2$ & 0.10 & NA \\
\hline
\end{tabular}

${ }^{a}$ All data are shown as the mean \pm SD. Data were analyzed with Kruskal-Wallis test followed by post-hoc Steel test. ${ }^{\dagger} p=0.05 v s$. no irradiation. NA: Not applicable.

deficiency [signatures 3 and 8 ; the aetiology of signature 8 is unknown, but its presence has been observed in breast cancer linked to BRCA deficiency (27)], and ii) cluster C, which showed weak similarity to multiple signatures associated with clusters A and B. There was, however, no obvious difference in the mutational signatures among the spontaneous and neutronand $\gamma$-ray-induced rat mammary carcinomas. In addition, no significant difference was observed among the carcinomas in the three groups with regard to the spectrum of mutations, the subtype or the age at detection. These results indicate that spontaneous and neutron- and $\gamma$-ray-induced rat mammary carcinomas all have a similar mutation spectrum.

Genes commonly targeted for mutation in spontaneous and neutron- and $\gamma$-ray-induced rat mammary carcinomas. To identify gene mutations potentially involved in the development of rat mammary carcinomas, nonsynonymous mutations, including missense, nonsense and splice site mutations, were extracted from the whole-exome sequencing data. As shown in Figure 7, we identified mutations in cancer genes listed in the COSMIC Cancer Gene Census (CGC) database (28) that are involved in DNA repair (e.g. Rad50, Brca2, Fance), cell cycle (e.g. Cdkn2a, Lzts1, Lats1), transcription (e.g. Prdm5, Camtal, Tp53, Cuxl, Mef2b), chromatin remodelling (e.g. Smarca2, Smarca4), cytoskeleton (e.g. Flna, Fat4), metabolism (e.g. Mtap), membrane transport (e.g. Abcg2) and signal transduction in MAPK (e.g. Epha2, Dusp6), Keap1/Nrf2 (e.g. Nfe2l2, Cul3), Pi3k/Akt (e.g. Pik3rl) or Wnt/ $\beta$-catenin (e.g. Cxxc4) pathways. Notably, focal copy-number losses in cancer genes were dominantly found in the carcinomas from the irradiated groups. In addition, we identified recurrent copynumber gains in 16p16 (Rps24 and Spin1) and 20p12 (Srsf3) and losses in 2q34 (Sycpl), 5q32 (Mtap, Cdkn2a and Cdkn2b), and $15 \mathrm{p} 12$ (Xkr6) regions in the carcinomas (Figure 8). Moreover, copy-number losses in 5q32 (Mtap, Cdkn2a and $C d k n 2 b)$ and 15p12 (Xkro) regions were identified only in the carcinomas from irradiated groups. These results suggest that mammary carcinomas in this rat model are induced probably through the induction of gene mutations similar to those found in human breast cancers and that mammary carcinomas induced by neutrons and $\gamma$-rays show focal copy-number losses in cancer genes as a radiation signature.

\section{Discussion}

Consistent with our previous report (11), this study demonstrated an increased incidence of hormone receptorpositive luminal mammary carcinoma in rats after neutronand $\gamma$-ray exposure as compared with non-irradiated controls. However, whole-exome sequencing of these mammary carcinomas revealed no significant difference in the number of somatic mutations among rat mammary carcinomas from non-irradiated and neutron- and $\gamma$-ray-irradiated groups. As shown in Tables II and IV, we also found that the period until the first palpation of mammary carcinomas in the irradiated groups was significantly shorter than that of the non-irradiated group, indicating an earlier induction of tumours in the irradiated groups. However, no increase in the number of somatic mutations was observed in the mammary carcinomas from the irradiated groups. These observations suggest that 
a

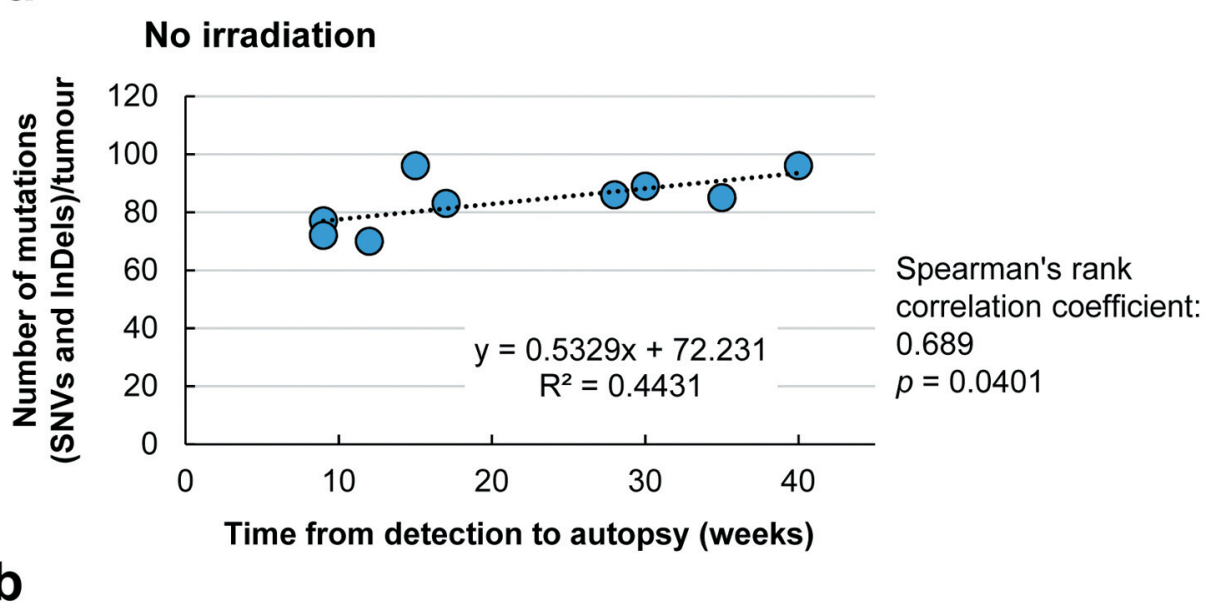

b

Neutrons

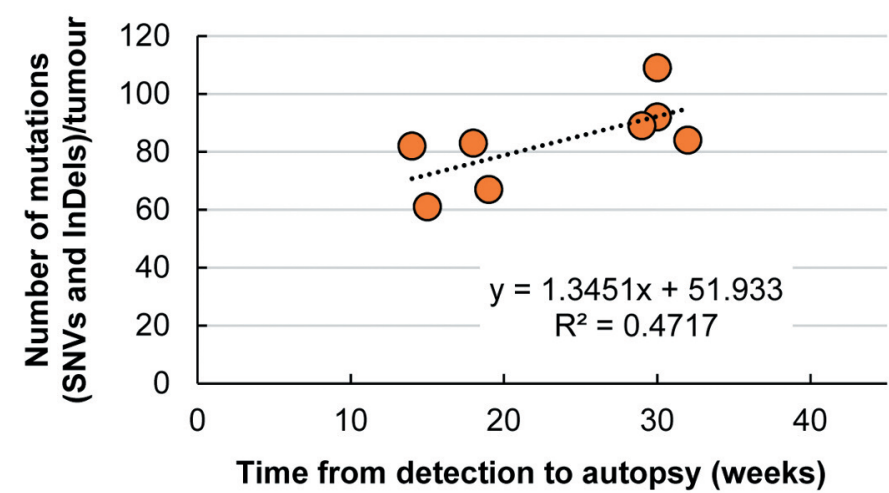

Spearman's rank correlation coefficient: 0.731 $p=0.0396$

C $\gamma$-rays

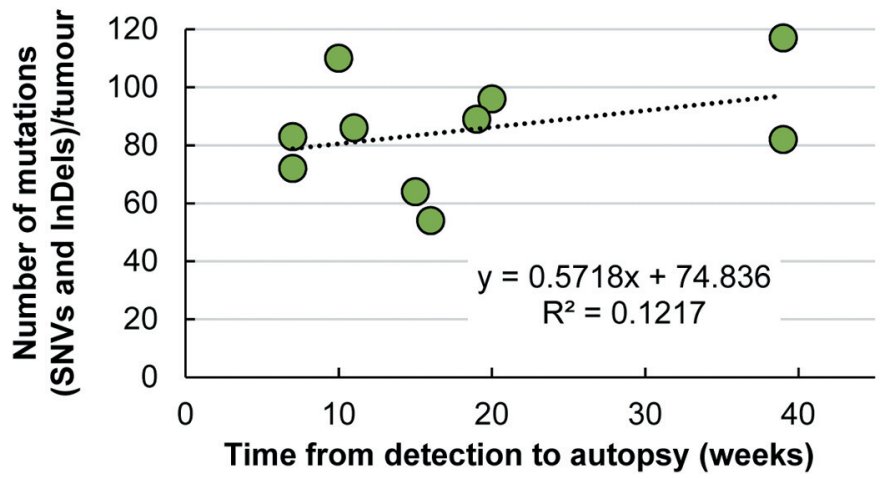

Spearman's rank correlation coefficient: 0.274 $p=0.443$

Figure 3. Correlation between the total number of somatic mutations (SNVs and InDels) and the growth period of rat mammary carcinomas. (a) Carcinomas ( $n=9)$ from non-irradiated rats. (b) Carcinomas $(n=8)$ from neutron-irradiated rats. (c) Carcinomas $(n=10)$ from $\gamma$-ray-irradiated rats.

radiation exposure increased the rate of somatic mutations for malignant transformation. Although ionizing radiation is known to induce genomic deletions (29), we noted relatively few deletion mutations in the mammary carcinomas from the irradiated groups. In addition, no difference in the spectrum of somatic mutations was observed among the carcinomas from the non-irradiated and neutron- and $\gamma$-ray-irradiated groups. Concerning this, it has been reported that genomic instability induced by ionizing radiation produces mutations across a spectrum similar to that occurring naturally (30). 


\section{a}

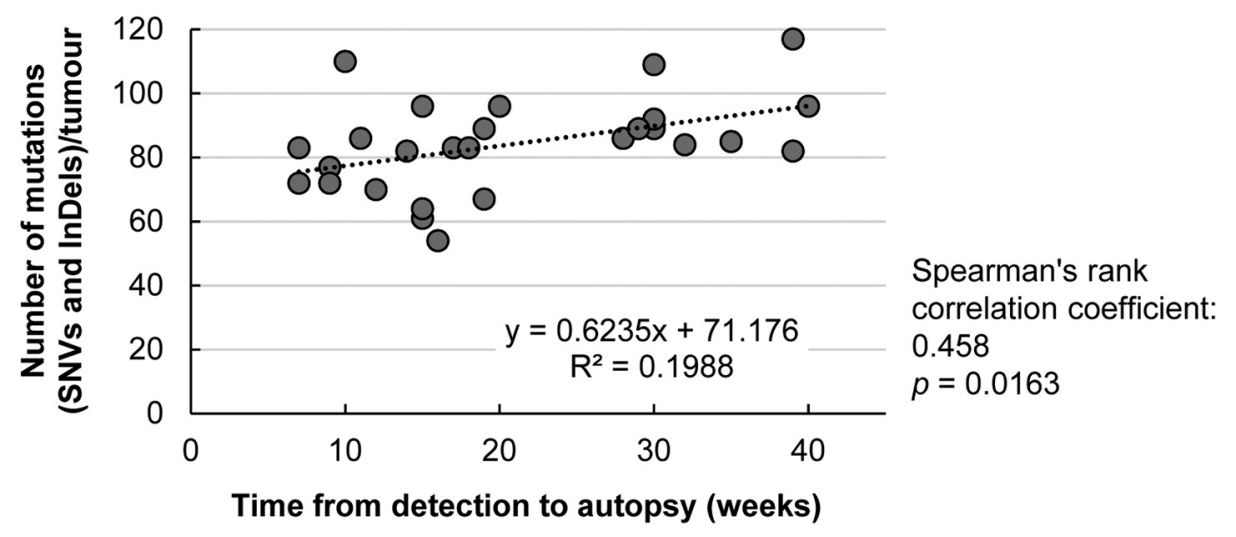

b

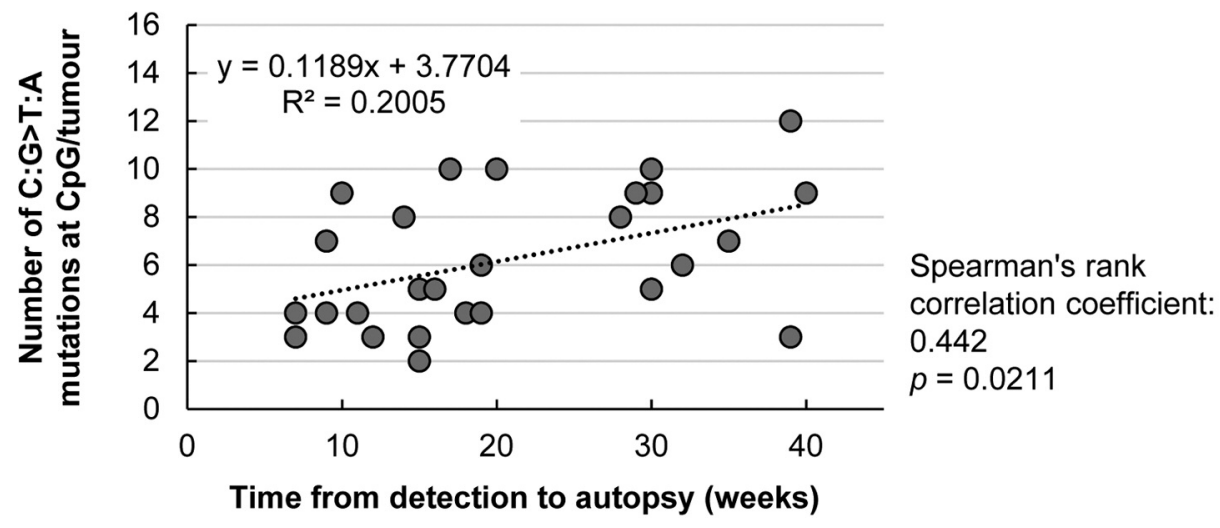

C

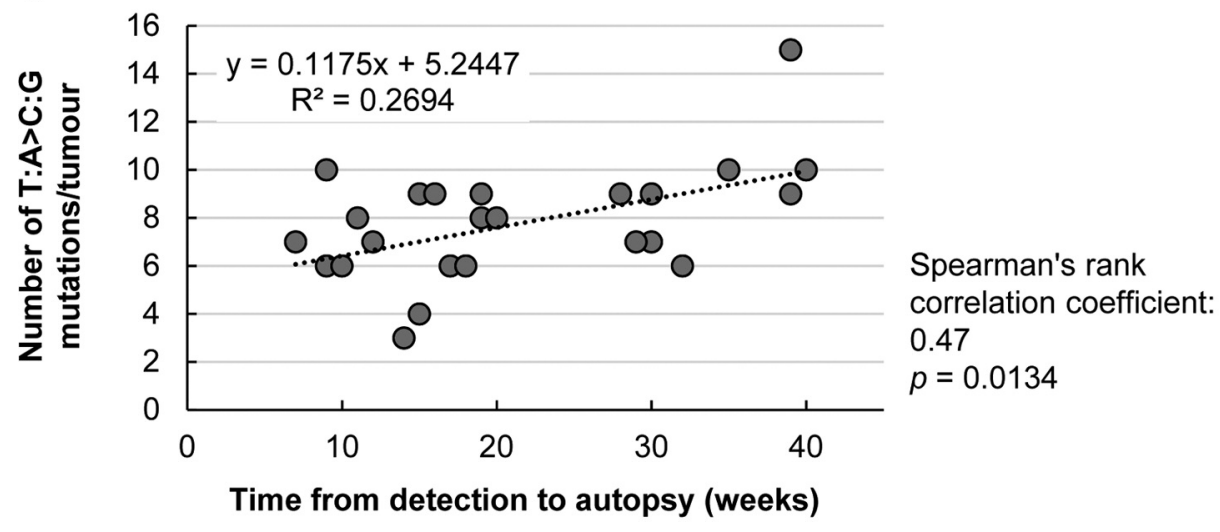

Figure 4. Correlation between the number of somatic mutations and the growth period of rat mammary carcinomas. (a) Correlation between the total number of somatic mutations (SNVs and InDels) and the duration of tumour growth for all palpable carcinomas ( $n=27)$. (b) Correlation between the number of $C: G>T: A$ transitions at $C p G$ sites and the duration of tumour growth for all palpable carcinomas ( $n=27)$. (c) Correlation between the number of $T: A>C: G$ transitions and the duration of tumour growth for all palpable carcinomas (n=27).

Thus, our findings suggest that radiation exposure accelerates the accumulation of somatic mutations required for tumour formation through the induction of a small number of mutations, such as deletions, directly induced by the radiation exposure and a large number of mutations induced by radiation-induced genomic instability.

Similar to spontaneous mammary carcinomas, the mutation spectrum of SNVs in mammary carcinomas from 
a

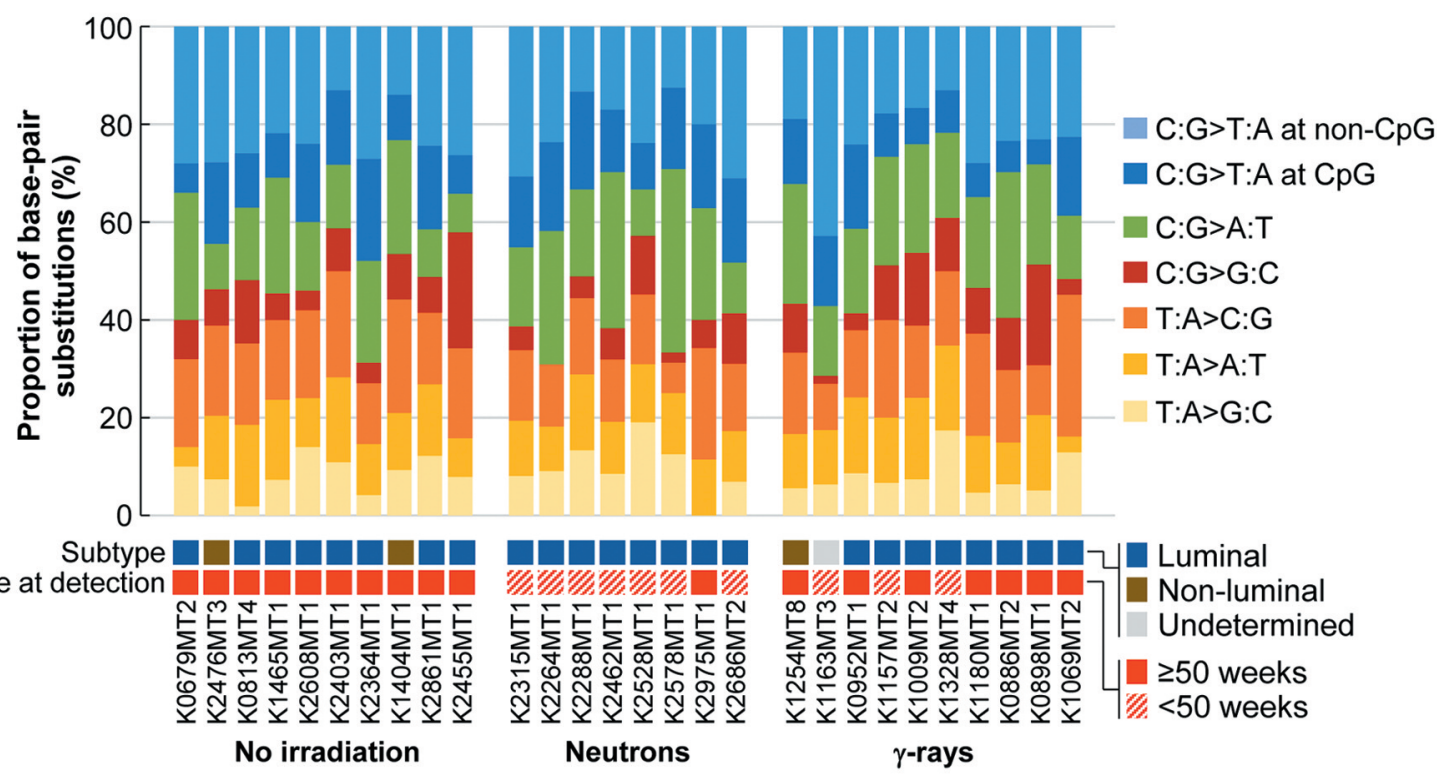

b

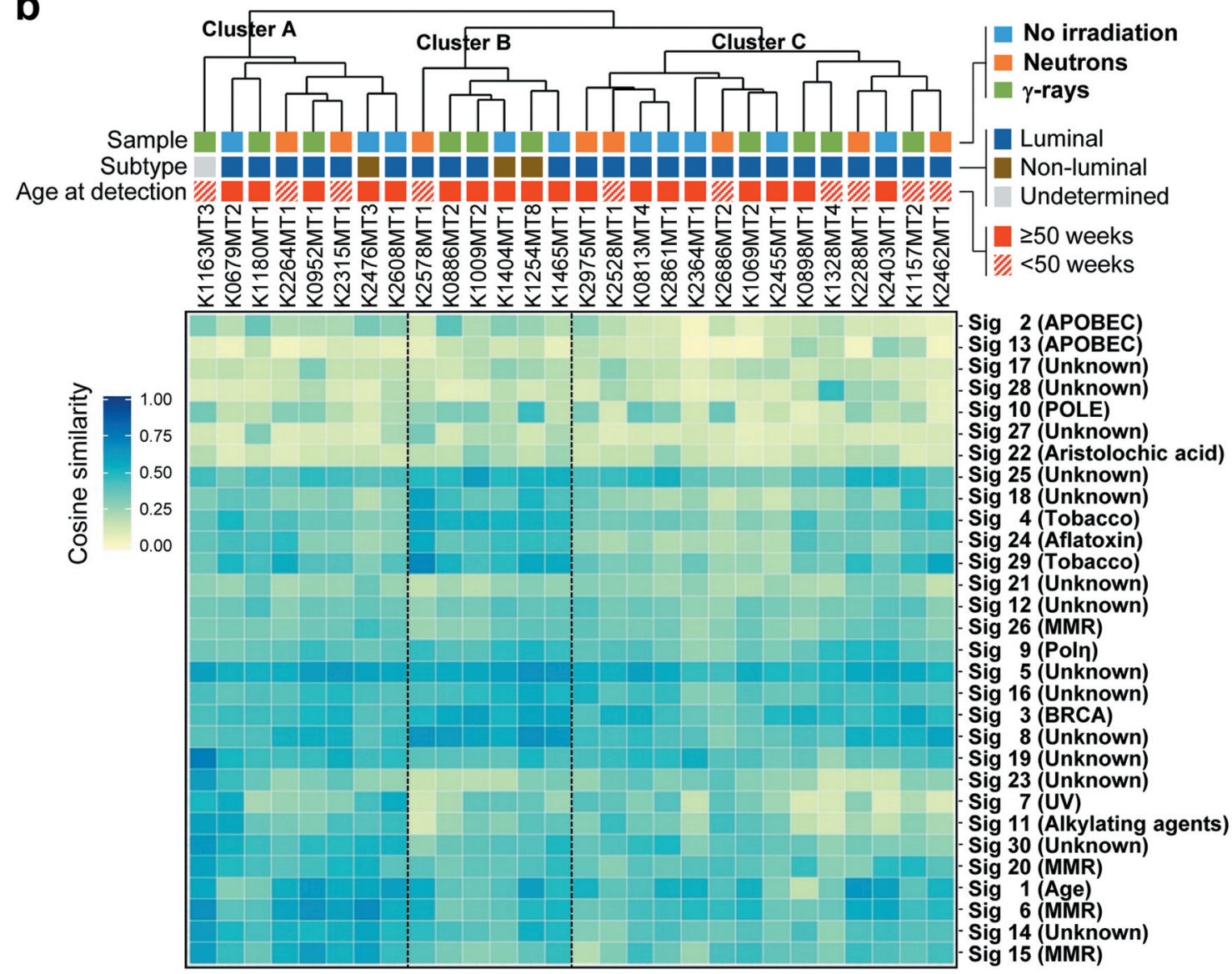

Figure 5. Mutational signatures in rat mammary carcinomas. (a) The proportions of seven possible base-pair substitutions among mutations for each carcinoma. (b) Similarity between mutational profiles of rat mammary carcinomas and COSMIC signatures. A heatmap showing the cosine similarity between the mutational profile of each rat mammary carcinoma and COSMIC signatures (Sig). Samples were classified by unsupervised hierarchical clustering. 

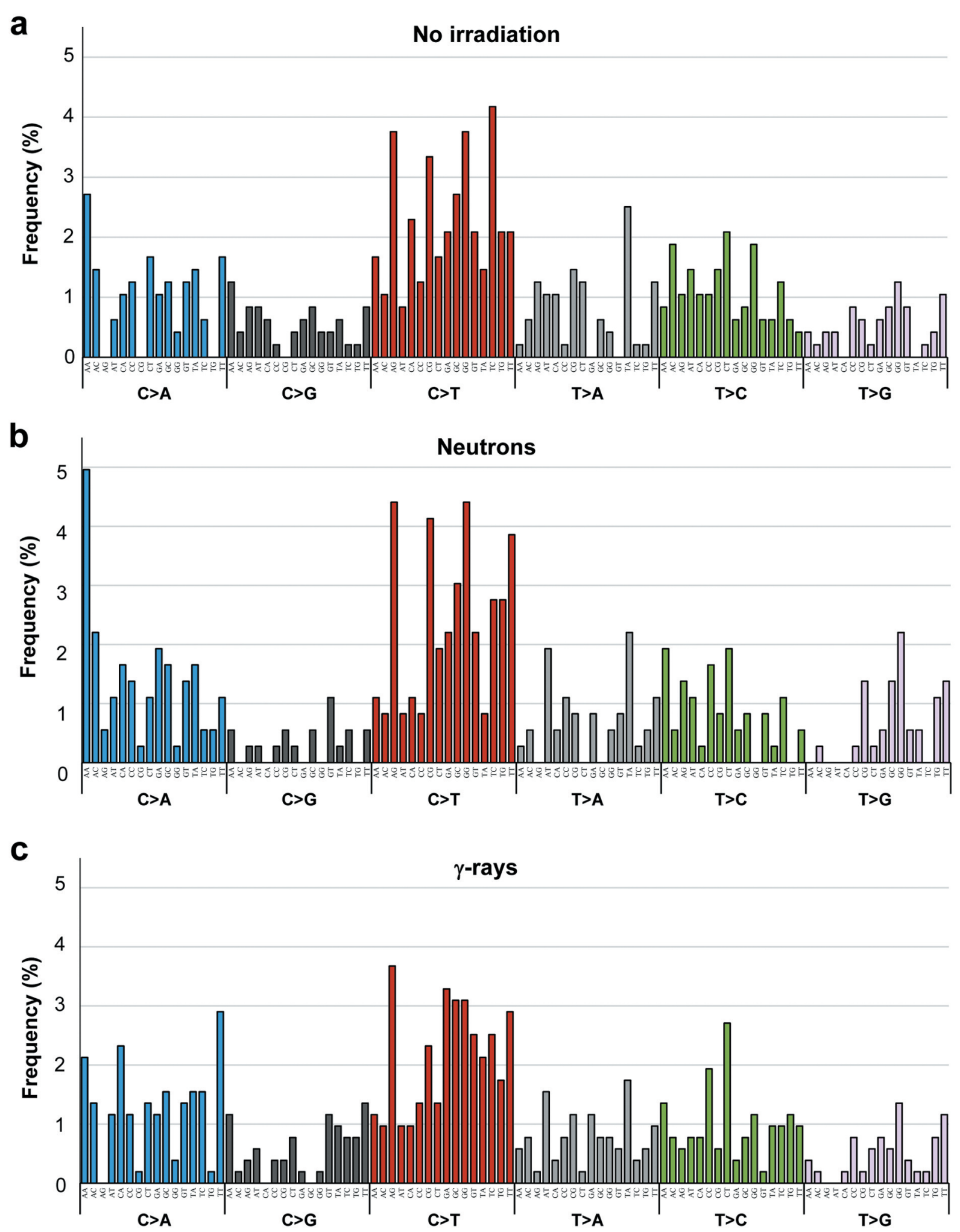

Figure 6. Mutational signatures identified in mammary carcinomas. (a-c) Data are shown for carcinomas from non-irradiated (a), neutron-irradiated (b) and $\gamma$-ray-irradiated (c) groups. Each signature is represented by the relative contribution (y axis) of 96 classes of mutations defined by base substitution and tri-nucleotide sequence context of the mutated base (x axis). The signatures were extracted from the SNV data pooled from 9 carcinomas from non-irradiated (a), 8 carcinomas from neutron-irradiated (b) and 10 carcinomas from $\gamma$-ray-irradiated (c) rats. 


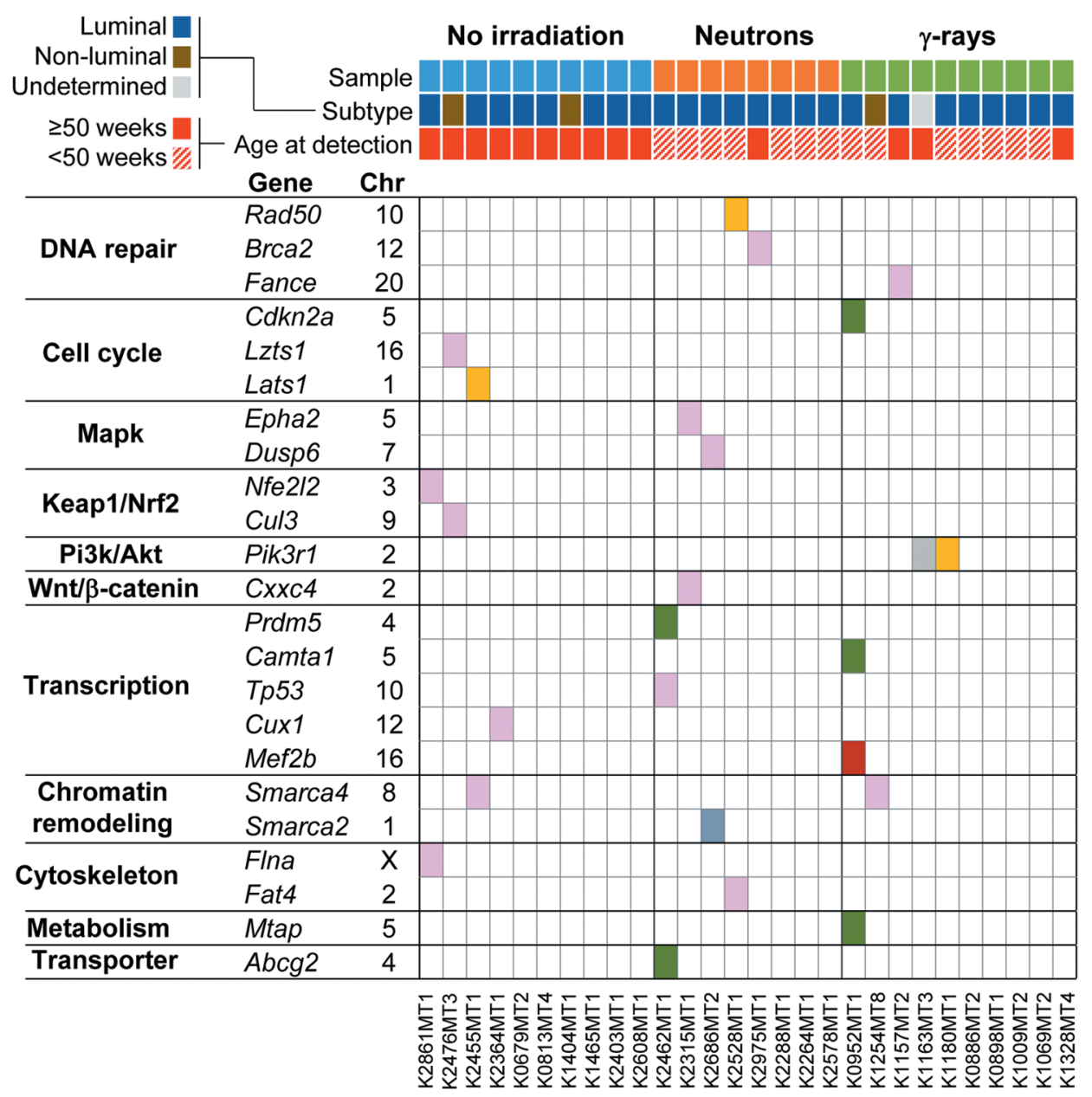

Mutation

Focal copy number gain

Missense $\quad$ Frameshift
Focal copy number loss (homozygous deletion)

In-frame deletion In-frame insertion

Figure 7. Cancer gene mutations identified in rat mammary carcinomas. Nonsynonymous somatic mutations and focal copy-number changes either oncogenes or tumour-suppressor genes listed in the COSMIC CGC are shown. Gene aberrations predicted to lead to the activation of at least a single allele of oncogenes or to inactivation of both alleles of tumour-suppressor genes were extracted.

the neutron- and $\gamma$-ray-irradiated groups was dominated by $\mathrm{C}: \mathrm{G}>\mathrm{T}: \mathrm{A}$ transitions (Figures $5 \mathrm{a}$ and 6 ). This observation is consistent with several reports that have shown genome-wide mutational patterns in rodent and human neoplasms associated with radiation exposure (31-33). Notably, although we did not found the mutation spectrum that distinguishs spontaneous and radiation-associated mammary carcinomas, Davidson et al. have reported mutational signatures associated with ionizing radiation in mouse and human tumours induced by fractionated high-dose irradiation (a total of 30-60 Gy at 2-3 Gy per fraction) (32). Thus, this discrepancy may reflect the difference in the total dose of irradiation. Ionizing radiation is also known to generate
ROS, which can induce premutagenic modifications of DNA bases, leading to the formation of 8 -oxoguanine $(25,34)$. However, no statistically significant difference in the frequency of $\mathrm{C}: \mathrm{G}>\mathrm{A}: \mathrm{T}$ transversion, which can be generated by misrepair of 8-oxoguanine lesion, was observed among the carcinomas from the non-irradiated and irradiated groups. Therefore, the production of ROS by ionizing radiation may have little contribution to the induction of gene mutations, although an increase in $\mathrm{C}: \mathrm{G}>\mathrm{A}: \mathrm{T}$ transversions was observed in some mammary carcinomas in the irradiated groups as compared with those in the non-irradiated group.

Animal studies have long been one of the principal sources of data for estimating the cancer risk of radiation 
a Chr $16(16 \mathrm{p} 16)$

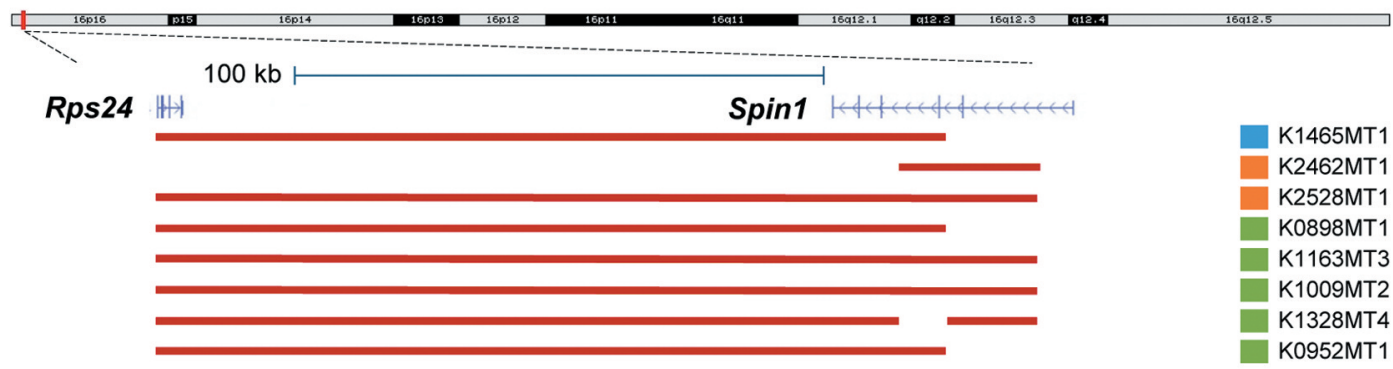

b Chr $20(20 p 12)$

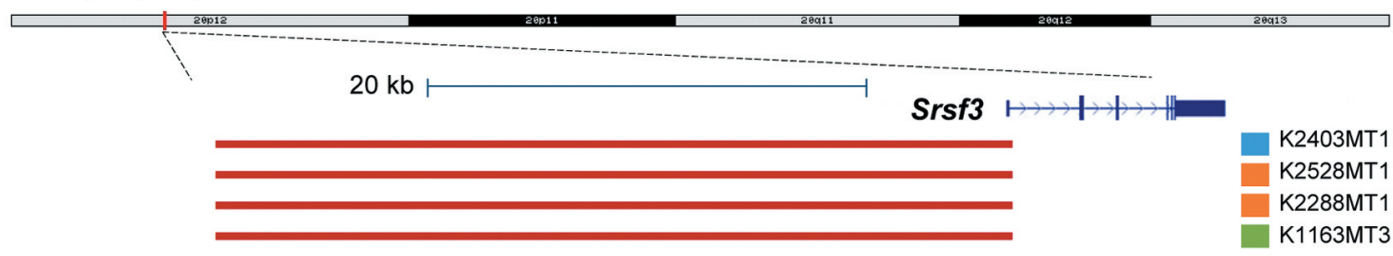

C Chr 2 (2q34)

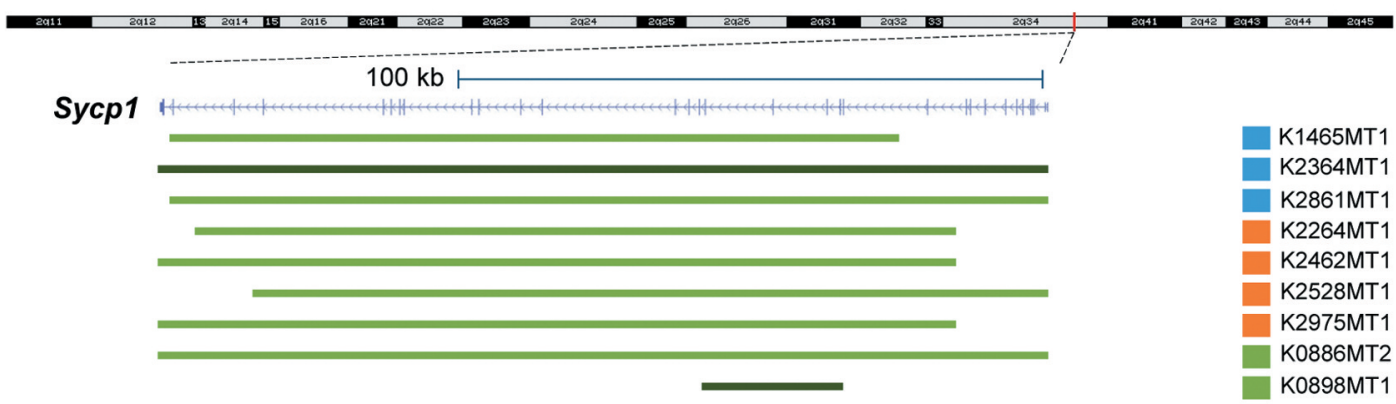

\section{d Chr $5(5 q 32)$}

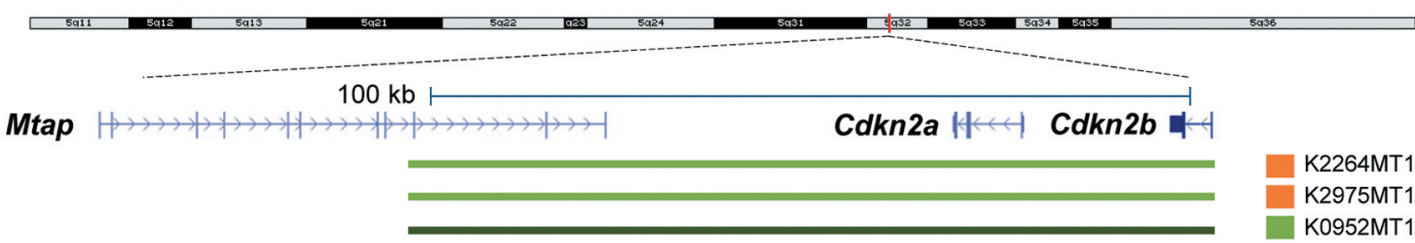

\section{e Chr 15 (15p12)}

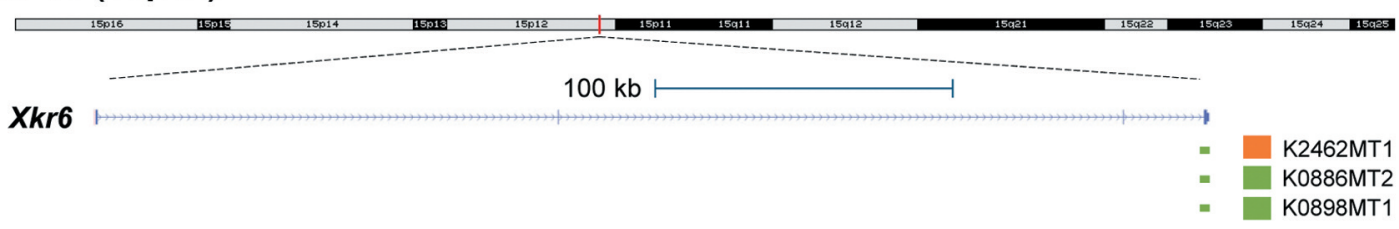

\begin{tabular}{lll}
\hline Copy number gain & No irradiation \\
Copy number loss (hemizygous deletion) & Neutrons \\
& $\gamma$-rays
\end{tabular}

Figure 8. Recurrent copy-number alterations in rat mammary carcinomas. (a-e) Copy-number gains in $16 p 16$ (a) and 20 p12 (b) and losses in $2 q 34$ (c), $5 q 32(d)$, and $15 p 12$ (e) regions are shown. 
exposure in humans due to a lack of or limited data for human populations (6). Additional data on the carcinogenic mechanisms related to radiation exposure are, however, needed to improve the level of confidence in extrapolating the results from animal studies to humans, because it has been shown that the particular gene alterations involved in a specific tumour type tend to differ across species based on comparisons of the rodent and human data of spontaneous and chemically induced tumours, with only limited data being available on radiation-induced tumours (6). Our whole-exome sequencing analysis revealed that mammary carcinomas that developed in those rats showed mutational patterns and gene mutations that were similar to those observed in human breast cancer (Figures $5 \mathrm{~b}$ and 7), suggesting that this is a suitable model for human breast cancer. Notably, nonsynonymous somatic mutations were identified in the rat mammary carcinomas in cancer genes, including Cdkn2a,Tp53, and Smarca 2/4, that are frequently mutated in various human cancers $(20,35)$. Mutations were also identified in genes involved in several pivotal signalling pathways, including Keap1/Nrf2, Pi3k/Akt and Wnt $/ \beta$-catenin, in human breast cancers $(20,36,37)$. These similarities strengthen our confidence in the extrapolation from data on rat mammary carcinoma to human breast cancer.

In the present study, focal copy-number losses were observed in rat mammary carcinomas predominately in the irradiated groups (Figures 7 and $8 \mathrm{c}$-e). In addition, as shown in Figure 8d, copy-number loss of chromosome 5 including the $C d k n 2 a$ locus was observed in mammary carcinomas only in the irradiated groups. With respect to this, our previous array-CGH analysis of rat mammary carcinomas also showed copy-number losses in this chromosomal region in the carcinomas in the irradiated groups $(11,38)$. Interestingly, consistent with these findings, loss of heterozygosity at chromosomal region 9q21 (CDKN2A locus) has been found to be significantly more common in human breast cancers after radiation therapy for Hodgkin's lymphoma than sporadic breast cancers (39). These observations suggest that focal copynumber loss in cancer genes is a signature for radiationinduced breast cancer.

Finally, the present data from this rat mammary cancer model provide fundamental new insights related to the extrapolation from the results obtained with this model to a better understanding of the risk and biology of human breast cancer induced by neutron and $\gamma$-ray exposure. Our findings may also be valuable for understanding the aetiology of cancers induced by radiation exposure.

\section{Conflicts of Interest}

The Authors declare no competing interests in relation to this study.

\section{Authors' Contributions}

HM, KD, TI and YS conceived and designed the experiments. HM, $\mathrm{KD}, \mathrm{TI}, \mathrm{MN}, \mathrm{YN}$ and MT performed the primary experiments, including animal experiments. HM and TM evaluated pathology. HM, MT and TI performed tumour subtyping. HM and AI performed the bioinformatics and statistical analysis. HM and KD analysed the results and wrote the manuscript. KD, TI, KI, MF, YS and SK supervised the study and reviewed the manuscript. All Authors read and approved the final manuscript.

\section{Acknowledgements}

The Authors thank all the technical staff at the Department of Radiation Effects Research, NIRS, QST. Part of this work was conducted in association with the Joint-use Research Facility for Collaborative Project with NIRS-NASBEE (14SP0008) and the NIRS project of Japan StoreHouse of Animal Radiobiology Experiments (J-SHARE). This work was supported in part by a Grant-in-Aid for Young Scientists (B) JP26740022 and for Scientific Research (A) JP15H01834 from the Japan Society for the Promotion of Science KAKENHI.

\section{References}

1 Preston DL, Ron E, Tokuoka S, Funamoto S, Nishi N, Soda M, Mabuchi K and Kodama K: Solid cancer incidence in atomic bomb survivors: 1958-1998. Radiat Res 168(1): 1-64, 2007. PMID: 17722996. DOI: 10.1667/RR0763.1

2 Covelli V, Coppola M, Di Majo V and Rebessi S: The doseresponse relationships for tumor induction after high-LET radiation. J Radiat Res 32: 110-117, 1991. PMID: 1823348. DOI: $10.1269 /$ jrr.32.supplement2_110

3 Taddei PJ, Mahajan A, Mirkovic D, Zhang R, Giebeler A, Kornguth D, Harvey M, Woo S and Newhauser WD: Predicted risks of second malignant neoplasm incidence and mortality due to secondary neutrons in a girl and boy receiving proton craniospinal irradiation. Phys Med Biol 55(23): 7067-7080, 2010. PMID: 21076189. DOI: 10.1088/0031-9155/55/23/S08

4 El Ghissassi F, Baan R, Straif K, Grosse Y, Secretan B, Bouvard V, Benbrahim-Tallaa L, Guha N, Freeman C, Galichet L, Cogliano V and WHO International Agency for Research on Cancer Monograph Working Group: A review of human carcinogens - part D: radiation. Lancet Oncol 10(8): 751-752, 2009. PMID: 19655431. DOI: 10.1016/s1470-2045(09)70213-x

5 Durante M, Orecchia R and Loeffler JS: Charged-particle therapy in cancer: Clinical uses and future perspectives. Nat Rev Clin Oncol 14(8): 483-495, 2017. PMID: 28290489. DOI: 10.1038/nrclinonc. 2017.30

6 NCRP, Extrapolation of Radiation-Induced Cancer Risks from Nonhuman Experimental Systems to Humans. Report No. 150, National Council on Radiation Protection and Measurements, Bethesda, MD, 2005.

7 Russo J: Significance of rat mammary tumors for human risk assessment. Toxicol Pathol 43(2): 145-170, 2015. PMID: 25714400. DOI: $10.1177 / 0192623314532036$

8 Imaoka T, Nishimura M, Iizuka D, Daino K, Takabatake T, Okamoto M, Kakinuma S and Shimada Y: Radiation-induced mammary carcinogenesis in rodent models: What's different 
from chemical carcinogenesis? J Radiat Res 50(4): 281-293, 2009. PMID: 19506345. DOI: 10.1269/jrr.09027

9 Imaoka T, Nishimura M, Daino K, Hosoki A, Takabatake M, Kokubo T, Doi K, Showler K, Nishimura Y, Moriyama H, Morioka T, Shimada Y and Kakinuma S: Age modifies the effect of 2-Mev fast neutrons on rat mammary carcinogenesis. Radiat Res 188(4): 419-425, 2017. PMID: 28809605. DOI: $10.1667 / R R 14829.1$

10 Imaoka T, Nishimura M, Daino K, Takabatake M, Moriyama H, Nishimura Y, Morioka T, Shimada Y and Kakinuma S: Risk of second cancer after ion beam radiotherapy: Insights from animal carcinogenesis studies. Int J Radiat Biol 95(10): 1431-1440, 2019. PMID: 30495977. DOI: 10.1080/09553002.2018.1547848

11 Moriyama H, Daino K, Imaoka T, Nishimura M, Nishimura Y, Takabatake M, Morioka T, Fukushi M, Shimada Y and Kakinuma S: Neutron-induced rat mammary carcinomas are mainly of luminal subtype and have multiple copy number aberrations. Anticancer Res 39(3): 1135-1142, 2019. PMID: 30842142. DOI: 10.21873/anticanres.13222

12 Coates AS, Winer EP, Goldhirsch A, Gelber RD, Gnant M, Piccart-Gebhart M, Thurlimann B, Senn HJ and Panel M: Tailoring therapies - improving the management of early breast cancer: St Gallen International Expert Consensus on the Primary Therapy of Early Breast Cancer 2015. Ann Oncol 26(8): 15331546, 2015. PMID: 25939896. DOI: 10.1093/annonc/mdv221

13 Neta G, Anderson WF, Gilbert E and Berrington A: Variation in the risk of radiation-related contralateral breast cancer by histology and estrogen receptor expression in seer. Breast Cancer Res Treat 131(3): 1021-1027, 2012. PMID: 22015617. DOI: 10.1007/s10549-011-1820-8

14 Broeks A, Braaf LM, Wessels LF, van de Vijver M, De Bruin ML, Stovall M, Russell NS, van Leeuwen FE and Van ' $t$ Veer LJ: Radiation-associated breast tumors display a distinct gene expression profile. Int J Radiat Oncol Biol Phys 76(2): 540-547, 2010. PMID: 20117289. DOI: 10.1016/j.ijrobp.2009.09.004

15 Yang XR, Killian JK, Hammond S, Burke LS, Bennett H, Wang Y, Davis SR, Strong LC, Neglia J, Stovall M, Weathers RE, Robison LL, Bhatia S, Mabuchi K, Inskip PD and Meltzer P: Characterization of genomic alterations in radiation-associated breast cancer among childhood cancer survivors, using comparative genomic hybridization (CGH) arrays. PLoS One 10(3): e0116078, 2015. PMID: 25764003. DOI: 10.1371/journal.pone.0116078

16 Morioka T, Blyth BJ, Imaoka T, Nishimura M, Takeshita H, Shimomura T, Ohtake J, Ishida A, Schofield P, Grosche B, Kulka U, Shimada Y, Yamada Y and Kakinuma S: Establishing the japan-store house of animal radiobiology experiments (JSHARE), a large-scale necropsy and histopathology archive providing international access to important radiobiology data. Int J Radiat Biol 95(10): 1372-1377, 2019. PMID: 31145030. DOI: $10.1080 / 09553002.2019 .1625458$

17 Imaoka T, Nishimura M, Daino K, Kokubo T, Doi K, lizuka D, Nishimura Y, Okutani T, Takabatake M, Kakinuma S and Shimada Y: Influence of age on the relative biological effectiveness of carbon ion radiation for induction of rat mammary carcinoma. Int J Radiat Oncol Biol Phys 85(4): 1134-1140, 2013. PMID: 23084769. DOI: $10.1016 /$ j.jirobp.2012.08.035

18 Task Group on Radiation Quality Effects in Radiological Protection, Committee 1 on Radiation Effects, International Commission on Radiological Protection: Relative biological effectiveness (RBE), quality factor (Q), and radiation weighting factor $(\mathrm{w}(\mathrm{R}))$. A report of the international commission on radiological protection. Ann ICRP 33(4): 1-117, 2003. PMID: 14614921. DOI: $10.1016 / \mathrm{s} 0146-6453(03) 00024-1$

19 Daino K, Ishikawa A, Suga T, Amasaki Y, Kodama Y, Shang Y, Hirano-Sakairi S, Nishimura M, Nakata A, Yoshida M, Imai T, Shimada Y and Kakinuma S: Mutational landscape of T-cell lymphoma in mice lacking the DNA mismatch repair gene Mlh1: No synergism with ionizing radiation. Carcinogenesis 40(2): 216-224, 2019. PMID: 30721949. DOI: $10.1093 /$ carcin/bgz013

20 Nik-Zainal S, Davies H, Staaf J, Ramakrishna M, Glodzik D, Zou X, Martincorena I, Alexandrov LB, Martin S, Wedge DC, Van Loo P, Ju YS, Smid M, Brinkman AB, Morganella S, Aure MR, Lingjaerde OC, Langerod A, Ringner M, Ahn SM, Boyault S, Brock JE, Broeks A, Butler A, Desmedt C, Dirix L, Dronov S, Fatima A, Foekens JA, Gerstung M, Hooijer GK, Jang SJ, Jones DR, Kim HY, King TA, Krishnamurthy S, Lee HJ, Lee JY, Li Y, McLaren S, Menzies A, Mustonen V, O’Meara S, Pauporte I, Pivot X, Purdie CA, Raine K, Ramakrishnan K, Rodriguez-Gonzalez FG, Romieu G, Sieuwerts AM, Simpson PT, Shepherd R, Stebbings L, Stefansson OA, Teague J, Tommasi S, Treilleux I, Van den Eynden GG, Vermeulen P, Vincent-Salomon A, Yates L, Caldas C, van't Veer L, Tutt A, Knappskog S, Tan BK, Jonkers J, Borg A, Ueno NT, Sotiriou C, Viari A, Futreal PA, Campbell PJ, Span PN, Van Laere S, Lakhani SR, Eyfjord JE, Thompson AM, Birney E, Stunnenberg HG, van de Vijver MJ, Martens JW, Borresen-Dale AL, Richardson AL, Kong G, Thomas G and Stratton MR: Landscape of somatic mutations in 560 breast cancer wholegenome sequences. Nature 534(7605): 47-54, 2016. PMID: 27135926. DOI: 10.1038 /nature 17676

21 Kanda Y: Investigation of the freely available easy-to-use software 'EZR' for medical statistics. Bone Marrow Transplant 48(3): 452458, 2013. PMID: 23208313. DOI: 10.1038/bmt.2012.244

22 Alexandrov LB, Nik-Zainal S, Wedge DC, Aparicio SA, Behjati S, Biankin AV, Bignell GR, Bolli N, Borg A, Borresen-Dale AL, Boyault S, Burkhardt B, Butler AP, Caldas C, Davies HR, Desmedt C, Eils R, Eyfjord JE, Foekens JA, Greaves M, Hosoda F, Hutter B, Ilicic T, Imbeaud S, Imielinski M, Jager N, Jones DT, Jones D, Knappskog S, Kool M, Lakhani SR, Lopez-Otin C, Martin S, Munshi NC, Nakamura H, Northcott PA, Pajic M, Papaemmanuil E, Paradiso A, Pearson JV, Puente XS, Raine K, Ramakrishna M, Richardson AL, Richter J, Rosenstiel P, Schlesner M, Schumacher TN, Span PN, Teague JW, Totoki Y, Tutt AN, Valdes-Mas R, van Buuren MM, van't Veer L, VincentSalomon A, Waddell N, Yates LR, Australian Pancreatic Cancer Genome I, Consortium IBC, Consortium IM-S, PedBrain I, Zucman-Rossi J, Futreal PA, McDermott U, Lichter P, Meyerson M, Grimmond SM, Siebert R, Campo E, Shibata T, Pfister SM, Campbell PJ and Stratton MR: Signatures of mutational processes in human cancer. Nature 500(7463): 415-421, 2013. PMID: 23945592. DOI: 10.1038/nature 12477

23 Tomasetti C, Vogelstein B and Parmigiani G: Half or more of the somatic mutations in cancers of self-renewing tissues originate prior to tumor initiation. Proc Natl Acad Sci USA 110(6): 1999-2004, 2013. PMID: 23345422. DOI: 10.1073/ pnas. 1221068110

24 Helleday T, Eshtad S and Nik-Zainal S: Mechanisms underlying mutational signatures in human cancers. Nat Rev Genet 15(9): 585-598, 2014. PMID: 24981601. DOI: $10.1038 / \mathrm{nrg} 3729$ 
25 Cheng KC, Cahill DS, Kasai H, Nishimura S and Loeb LA: 8Hydroxyguanine, an abundant form of oxidative DNA damage, causes $\mathrm{G}-\mathrm{T}$ and $\mathrm{A}-\mathrm{C}$ substitutions. J Biol Chem 267(1): 166-172, 1992. PMID: 1730583.

26 Forbes SA, Bhamra G, Bamford S, Dawson E, Kok C, Clements J, Menzies A, Teague JW, Futreal PA and Stratton MR: The Catalogue of Somatic Mutations in Cancer (COSMIC). Curr Protoc Hum Genet Chapter 10: Unit 10 11, 2008. PMID: 18428421. DOI: $10.1002 / 0471142905$.hg1011s57

27 Davies H, Glodzik D, Morganella S, Yates LR, Staaf J, Zou X, Ramakrishna M, Martin S, Boyault S, Sieuwerts AM, Simpson PT, King TA, Raine K, Eyfjord JE, Kong G, Borg A, Birney E, Stunnenberg HG, van de Vijver MJ, Borresen-Dale AL, Martens JW, Span PN, Lakhani SR, Vincent-Salomon A, Sotiriou C, Tutt A, Thompson AM, Van Laere S, Richardson AL, Viari A, Campbell PJ, Stratton MR and Nik-Zainal S: HRDetect is a predictor of BRCA1 and BRCA2 deficiency based on mutational signatures. Nat Med 23(4): 517-525, 2017. PMID: 28288110. DOI: $10.1038 / \mathrm{nm} .4292$

28 Sondka Z, Bamford S, Cole CG, Ward SA, Dunham I and Forbes SA: The COSMIC Cancer Gene Census: Describing genetic dysfunction across all human cancers. Nat Rev Cancer 18(11): 696-705, 2018. PMID: 30293088. DOI: 10.1038/s41568018-0060-1

29 Little JB: Radiation carcinogenesis. Carcinogenesis 21(3): $397-$ 404, 2000. PMID: 10688860. DOI: 10.1093/carcin/21.3.397

30 Little JB, Nagasawa H, Pfenning T and Vetrovs H: Radiationinduced genomic instability: Delayed mutagenic and cytogenetic effects of X rays and alpha particles. Radiat Res 148(4): 299307, 1997. PMID: 9339945.

31 Sherborne AL, Davidson PR, Yu K, Nakamura AO, Rashid M and Nakamura JL: Mutational analysis of ionizing radiation induced neoplasms. Cell Rep 12(11): 1915-1926, 2015. PMID: 26344771. DOI: 10.1016/j.celrep.2015.08.015

32 Davidson PR, Sherborne AL, Taylor B, Nakamura AO and Nakamura JL: A pooled mutational analysis identifies ionizing radiation-associated mutational signatures conserved between mouse and human malignancies. Sci Rep 7(1): 7645, 2017. PMID: 28794481. DOI: 10.1038/s41598-017-07888-0
33 Rose Li Y, Halliwill KD, Adams CJ, Iyer V, Riva L, Mamunur R, Jen KY, Del Rosario R, Fredlund E, Hirst G, Alexandrov LB, Adams D and Balmain A: Mutational signatures in tumours induced by high and low energy radiation in Trp53 deficient mice. Nat Commun 11(1): 394, 2020. PMID: 31959748. DOI: 10.1038/s41467-019-14261-4

34 Douki T, Delatour T, Paganon F and Cadet J: Measurement of oxidative damage at pyrimidine bases in gamma-irradiated DNA. Chem Res Toxicol 9(7): 1145-1151, 1996. PMID: 8902270. DOI: $10.1021 /$ tx960095b

35 Vogelstein B, Papadopoulos N, Velculescu VE, Zhou S, Diaz LA, Jr. and Kinzler KW: Cancer genome landscapes. Science 339(6127): 1546-1558, 2013. PMID: 23539594. DOI: $10.1126 /$ science. 1235122

36 Cancer Genome Atlas N: Comprehensive molecular portraits of human breast tumours. Nature 490(7418): 61-70, 2012. PMID: 23000897. DOI: $10.1038 /$ nature 11412

37 Jaramillo MC and Zhang DD: The emerging role of the Nrf2Keap1 signaling pathway in cancer. Genes Dev 27(20): 2179 2191, 2013. PMID: 24142871. DOI: 10.1101/gad.225680.113

38 Iizuka D, Imaoka T, Takabatake T, Nishimura M, Kakinuma S, Nishimura $Y$ and Shimada Y: DNA copy number aberrations and disruption of the p16Ink4a/Rb pathway in radiation-induced and spontaneous rat mammary carcinomas. Radiat Res 174(2): 206215, 2010. PMID: 20681787. DOI: 10.1667/RR2006.1

39 Behrens C, Travis LB, Wistuba, II, Davis S, Maitra A, Clarke EA, Lynch CF, Glimelius B, Wiklund T, Tarone R and Gazdar AF: Molecular changes in second primary lung and breast cancers after therapy for Hodgkin's disease. Cancer Epidemiol Biomarkers Prev 9(10): 1027-1035, 2000. PMID: 11045784.

Received October 26, 2020

Revised November 13, 2020

Accepted November 14, 2020 